\title{
Comparison of the etiologic, microbiologic, clinical and outcome characteristics of febrile vs. non-febrile neutropenia in hospitalized immunocompetent children
}

\author{
Eugene Leibovitz ${ }^{1,2,3,4}$. Joseph Kapelushnik ${ }^{1,2,3} \cdot$ Sabrin Alsanaa ${ }^{1,2,3}$ - Dov Tschernin ${ }^{1,2,3}$ - Ruslan Sergienko ${ }^{3,5}$. \\ Ron Leibovitz ${ }^{1,3} \cdot$ Julia Mazar ${ }^{2,3,6} \cdot$ Yariv Fruchtman ${ }^{1,2,3}$
}

Received: 15 January 2020 / Accepted: 1 June 2020 / Published online: 27 July 2020

(C) Springer-Verlag GmbH Germany, part of Springer Nature 2020

\begin{abstract}
We compared the etiologic, microbiologic, clinical, and outcome picture among febrile and non-febrile immunocompetent children hospitalized during 2013-2015 with acute neutropenia (absolute neutrophil count $<1.5 \times 10^{9} / \mathrm{L}$ ). Serious bacterial infections (SBI) were defined as culture-positive blood, urine, cerebrospinal fluid, articular fluid or stool infections, pneumonia, brucellosis, and rickettsiosis. Overall, 664 children $<18$ years of age were enrolled; $407(62.2 \%)$ had fever $>38.0{ }^{\circ} \mathrm{C}$ and 247 (37.8\%) were non-febrile at admission. There were $425(64.0 \%), 125(18.8 \%), 48(7.2 \%)$, and $66(9.9 \%)$ patients aged 0-24 months, 2-6, 7-12, and $>12$ years, respectively. No differences were recorded in the distribution of febrile vs. non-febrile patients among the age groups nor among the 3 neutropenia severity groups $\left(<0.5,0.5-1.0\right.$ and $\left.1.0-1.5 \times 10^{9} / \mathrm{L}\right)$. SBI infections were diagnosed in 98 (14.8\%) patients, with higher rates among febrile patients vs. non-febrile patients (16.8\% vs. $11.5 \%, P=0.06)$. Brucellosis and rickettsiosis were diagnosed in $15.4 \%$ and $23.1 \%$ tests performed, respectively. 295/688 (42.9\%) virologic examinations returned positive. Among patients $<24$ months, more febrile ones had viral infectious compared with afebrile patients $(P=0.025)$. Acute leukemia was diagnosed in 6 patients. Neutropenia resolved in 163/323 (50.5\%) patients during a 1month follow-up. No differences were recorded in neutropenia resolution between febrile and non-febrile children among all 3 severity groups. Severe neutropenia was rare and occurred mainly in very young patients. SBIs were more common among febrile patients compared with non-febrile patients, but there was no association between severity of neutropenia or its resolution and the presence or absence of fever at diagnosis.
\end{abstract}

Keywords Neutropenia $\cdot$ Children $\cdot$ Serious bacterial infections $\cdot$ Leukemia $\cdot$ Follow-up

Eugene Leibovitz

eugenel@bgu.ac.il

1 Division of Pediatrics, Soroka University Medical Center, Beer Sheva, Israel

2 Soroka University Medical Center, Beer Sheva, Israel

3 Faculty of Health Sciences, Ben-Gurion University, Beer Sheva, Israel

4 Pediatric Infectious Disease Unit, Soroka University Medical Center, P.O. Box 151, 84101 Beer Sheva, Israel

5 Epidemiology Department, Soroka University Medical Center, Beer Sheva, Israel

6 Laboratory of Hematology, Soroka University Medical Center, Beer Sheva, Israel

\section{Introduction}

Neutropenic oncologic immunocompromised patients have a significant risk of serious infections when diagnosed with an absolute neutrophil count (ANC) $<1.0$ cells $\times 10^{9}$ and especially when the ANC decreases to $<0.1$ cells $\times 10^{9} / \mathrm{L}[1-4]$. On the other hand, acute transient neutropenia (defined as an absolute neutrophil count, ANC, $<1.5$ cells $\times 10^{9} / \mathrm{L}$ ) in immunocompetent patients is mainly a benign and transient condition related to an intercurrent viral infection, particularly in afebrile patients [5-8]. In immunocompetent febrile patients, while a viral etiology is still common, serious bacterial infections (SBI) should always be taken into consideration $[8,9]$.

In the nine studies (two prospective) published in the pediatric medical literature during 2010-2020 and dealing with the topic of acute neutropenia diagnosed in immunocompetent children, 7 enrolled only febrile patients while the other 2 
enrolled both non-febrile and febrile neutropenic patients [10-18]. The number of patients described varied from study to study (range 32-1888) and the majority of patients were younger than 2 years of age (range $47-86.4 \%$ ). The percentages of patients with severe neutropenia $(\mathrm{ANC}<0.5$ cells $\times$ $10 \% / \mathrm{L}$ ) ranged from 8.5 to $100 \%$ (two studies $[10,16]$ enrolled only patients with severe neutropenia) [16-18]. The rates of SBIs among the enrolled patients were reported in six studies and ranged from 1.9 to $23.6 \%$ [10, 12, 14-17]. No SBIs were reported in two studies $[10,11]$. Infectious diseases were associated with acute neutropenia in $12.1-63.8 \%$ patients [13, $14,16,18]$. Bacterial infections associated with neutropenia were reported in $5.3-21.9 \%$ patients $[10,14,16,18]$. Viral investigations were completed in five studies $[12-14,16,18]$ and the isolation ranges were between 5.1 and $55 \%$ of the enrolled patients. In the two studies where a detailed definitive viral diagnosis was reported, human herpes virus 6 , enteroviruses, and influenza A virus [12] and RSV; influenza A; and parainfluenza 1 viruses [18] were the most commonly isolated pathogens. In one of the two studies completed in Greece, neutropenia following a Coxackie, mumps, EBV, or RSV infection lasted for more than 1 month [13]. Malignancies associated with acute neutropenia were diagnosed in two studies $[14,18]$ at rates of $0.8-2.6 \%$ and included acute lymphoblastic leukemia and myelodysplasia. The mean time for recovery of the ANC in evaluable patients ranged from 6 to 16.7 days $[12,16]$.

The published studies reporting on acute neutropenia in immunocompetent infants and children were characterized by lack by heterogeneity in terms of patient enrollment criteria, investigations performed and appropriate follow-up. The information on the risk of SBIs in the patients with severe neutropenia is also limited, the management of these patients is controversial and there is agreement that a more prudent approach is warranted in these patients [19]. Furthermore, none of the presented studies made a direct comparison between febrile and non-febrile neutropenic immunocompetent patients in respect to severity of the condition, its various etiologies, management, and outcome. Therefore, the main purpose of the present study was to describe and compare the epidemiologic, etiologic, microbiologic, clinical, and outcome characteristics of febrile and non-febrile immunocompetent children hospitalized with acute neutropenia at the Soroka University Medical Center (SUMC), Beer-Sheva, Israel, during 2013-2015.

\section{Patients and methods}

This retrospective study was conducted at the pediatric departments of the SUMC during a 3-year period (1.1.201331.12.2015). The pediatric division of the hospital received approximately 40,000 visits per year during the study period.
Children presenting with new neutropenia and hospitalized because of this condition constituted the study cohort. Patients with previous history of neutropenia (like chronic, cyclic or autoimmune neutropenia, or aplastic anemia) ) and with any primary diagnoses known to cause neutropenia like malignancy (leukemia, lymphoma, solid tumors, brain tumors), immunosuppressive disorders (primary immunodeficiencies, cystic fibrosis, systemic erythematous lupus, rheumatoid arthritis, or chronic steroid therapy), and therapies or medications causing neutropenia were excluded from the study.

The study was conducted after obtaining approval from the ethics committee of SUMC.

Patients were evaluated in the Emergency Department, during hospitalization (where additional WBC counts were performed) and at the outpatient pediatric clinics (at least once during a one-month follow-up after discharge, when WBC measurements were repeated). All patients had the medical record reviewed for demographic and history data, clinical and laboratory findings (presence/absence of fever, risk factors for SBI, total WBC count, ANC and the results of urine, blood, and/or cerebrospinal fluid culture, serology and virology tests), disease management, and follow-up.

\section{Neutropenia}

Neutropenia was defined as an ANC $<1.5 \times 10^{9} / \mathrm{L}$. According to severity, neutropenia was defined as severe (ANC $<0.5 \times$ $10^{9} / \mathrm{L}$ ), moderate (ANC between 0.5 and $1.0 \times 10^{9} / \mathrm{L}$ ), or mild (ANC between 1.0 and $1.5 \times 10^{9} / \mathrm{L}$ ). Leukopenia was defined as a total WBC count of $<5.0 \times 10^{9} / \mathrm{L}$. Thrombocytopenia was defined as a platelet count of $<150.0 \times 10^{9} / \mathrm{L}$. Anemia was defined as hemoglobin value greater than two standard deviations below the mean for reference population.

\section{Serious bacterial infections}

The following infections were considered SBIs for the purpose of the study: bacteremia, bacterial meningitis, pneumonia, urinary tract infection, bacterial gastroenteritis, osteomyelitis and septic arthritis [8, 9, 20,21]. Diagnosis of UTI was made on the basis of (1) the presence of at least 50,000 colonies $/ \mathrm{ml}$ of one uropathogenic organism in a specimen of urine obtained by bladder catheterization or suprapubic aspiration in patients $<2$ years of age and urine midstream for older patients and (2) a positive urinalysis by dipstick.

All cases of pneumonia included were alveolar as this was considered suggestive of a bacterial etiology. Brucellosis and rickettsiosis were also considered SBIs.

\section{Microbiology}

Blood cultures were performed using the Bactec Becton Dickinson (Benex Limited, Shannon, County Clare, Ireland) 
system; the Vitel Bio Merieux (Boston, MA) system was used for bacterial identification. Cerebrospinal fluid was examined by culture for conventional bacterial pathogens and by polymerase chain reaction (PCR) (when recommended) for herpes simplex viruses 1 and 2 and enteroviruses. Serum samples were tested for VCA-IgM and EBNA-IgG antibodies for Epstein-Barr virus and cytomegalovirus. Skin lesions were examined for herpes simplex virus by PCR.

All the respiratory viruses were tested simultaneously with a multiplex real-time polymerase chain reaction (mqRT-PCR) able to identify 12 respiratory viruses [22]. Each sample was tested in parallel, in three test tubes, for the following viruses: influenza $\mathrm{A}$ and $\mathrm{B}$, parainfluenza 2 and 3, human respiratory syncytial virus (RSV), human metapneumovirus (hMPV), rhinovirus, adenovirus, and coronaviruses 229E, HKU1, OC43, and NL63. Amplification was carried using the RNA UltraSense One-Step qRT-PCR System (Invitrogen, Carlsbad, CA, USA). The sensitivity rate was identical at $100 \%$ for all virus groups except coronaviruses, in which the sensitivity of the pooled samples was $89.3 \%$.

Diagnosis of brucellosis was established according to a clinical presentation compatible with the disease, a positive blood culture, and/or a standard tube agglutination test titer $>1 / 160$ obtained at admission in all patients [23, 24]. Diagnosis of rickettsiosis was established by determining the presence of IgG and IgM antibodies to murine typhus and spotted fever group rickettsia, by using a micro immunofluorescence assay [25].

\section{Management}

The indications for hospitalization included (1) neutropenia < $500 \mathrm{WBC} \times 10^{9} / \mathrm{L} ; 2$ ) the clinical status of the neutropenic patient; (3) the infectious focus diagnosed and the need for initiation of intravenous antibiotic treatment (like pneumonia, urinary tract, dysentery); and (4) diagnosis or suspicion of brucellosis and rickettsiosis, need for initiation of empiric or definitive antibiotic treatment for these two diseases and need for patient monitoring during hospitalization.

During the study period, the management of patients with neutropenia was dictated by patients' condition and neutropenia severity. Ill-appearing patients, regardless of neutropenia severity, and those with severe neutropenia $<0.5$ cells $\times 10^{9} / \mathrm{L}$ were considered at risk of SBI, were hospitalized, and then started on empiric broad-spectrum antibiotics after obtaining at least 1 blood culture.

Every hospitalized patient was followed, after admission, with at least one WBC count during hospitalization or during the one-month follow-up period after discharge.

\section{Data analysis}

Data analysis was conducted using the SPSS 22.0 package. Analysis of variance and $t$ tests were used to compare continuous variables. The $\chi 2$ or Fisher exact tests were used for comparison of categorical variables. Kaplan-Meier survival curves were built for the three neutropenia severity groups, and these groups were compared with the use of the log-rank test. $P$ values $<0.05$ were considered significant.

\section{Results}

Overall, 664 previously healthy, presumed immunocompetent infants and children $<18$ years of age (the study population) were diagnosed with acute neutropenia and hospitalized at the pediatric departments of SUMC. Of them, 411 (61.9\%) had a body temperature $>38.0^{\circ} \mathrm{C}$ and $253(38.1 \%)$ were non-febrile at admission. There were $220(33.1 \%)$ Jewish patients and 434 (65.4\%) Bedouin patients (data on ethnicity was missing in $10,1.5 \%$ patients). There were $370(55.7 \%)$ male and 294 $(44.3 \%)$ female patients. There were $425(64.0 \%), 125$ (18.8\%), $48(7.2 \%)$, and $66(9.9 \%)$ patients aged 0-2, 3-6, $7-12$, and $>12$ years, respectively. No differences were recorded in the distribution of febrile vs. non-febrile patients among these 4 age groups, respectively $(P=0.691)$. None of the enrolled patients suffered from previously diagnosed immunocompromising diseases, malignancies, or hematologic conditions associated with neutropenia.

The most common clinical conditions/symptoms associated with neutropenia at admission included (according to the involved body system) the respiratory, urinary, skin, nervous, and otolaryngology systems and were diagnosed as bronchiolitis, vomiting, urinary tract infection, rash, afebrile convulsions, and tonsillitis $(31,25,21,18,10$, and 10 cases, respectively). More cases of upper respiratory tract infections were diagnosed in the group of patients with fever $>38.0^{\circ} \mathrm{C}$ compared with afebrile patients $(6.1 \%$ vs. $1.6 \%)$. No other significant differences in the distribution of the conditions/ symptoms associated with neutropenia at admission were recorded when comparing the febrile and the non-febrile patient groups.

Of the 664 enrolled patients, 24 (3.6\%), 71 (10.7\%), 213 (32.1\%), and $356(53.6 \%)$ had neutrophil counts $<200,200$ 500, 501-1000, and 1001-1500 cells $\times 10^{9} / \mathrm{L}$, respectively. Overall, $95(14.3 \%)$ patients suffered from severe neutropenia $\left(<500 \times 10^{9} / \mathrm{L}\right)$. The distribution of patients among the four neutropenia groups was not different between the febrile and the non-febrile groups of patients $(P=0.175)$. There were $42.4 \%, 24.8 \%$, and $21.0 \%$ patients with leukopenia, anemia, and thrombocytopenia, respectively. While no differences were recorded between the febrile and non-febrile patient groups with respect to the distribution of leukopenia and thrombocytopenia cases, more patients suffering from anemia were recorded in the non-febrile vs. the febrile group $(29.8 \%$ vs. $21.8 \%, P=0.03)$. 
Among the 411 neutropenic febrile patients, no differences were recorded in the patient distribution within the four neutropenia severity groups between the patients with a fever between $38.0-39.0^{\circ} \mathrm{C}$ and the patients with fever $>39.0^{\circ} \mathrm{C}$ $(P=0.127)$ and no differences were recorded between these two febrile patients groups in respect to the distribution of leukopenia, anemia, and thrombocytopenia.

\section{Etiology}

\section{Bacterial infections (Table 1)}

Positive blood cultures were recorded in 12/633 (1.9\%) evaluable patients. The most frequently isolated organisms were Staphylococcus aureus, Enterobacter, and Brucella (four, two, and two patients, respectively). Brucellosis was diagnosed in 20 patients (two positive blood cultures, 19 positive serologies, 1 patient with both positive blood culture and positive serology, one patient with positive blood cultures and negative serology). No differences were recorded in the distribution of brucellosis cases among febrile vs. non-febrile patients. Rickettsiosis was found in 14 (20.6\% of the evaluated patients), with no differences between febrile and nonfebrile patients. Overall, Brucella and rickettsial infections were diagnosed in 34 (5.1\%) patients. No cases of meningitis were recorded. Sixteen cases of alveolar pneumonia were diagnosed, 12 in febrile patients, and four in non-febrile patients $(P=0.405)$. Urine cultures were performed in $205(30.9 \%)$ neutropenic patients and returned positive in $34(16.6 \%)$; Escherichia coli and Klebsiella spp. were the most commonly isolated uropathogens, with no differences in distribution between febrile and non-febrile patients.

Overall, bacterial infections were recorded in 96 (14.5\%) neutropenic patients with a trend to higher percentages in febrile patients compared with non-febrile patients $(16.3 \%$ vs. $11.5 \%, P=0.085)$. Serious bacterial infections were diagnosed in 98 (14.8\%) neutropenic patients, with higher rates among febrile patients compared with non-febrile patients ( $16.8 \%$ vs. $11.5 \%, P=0.06$ ).

Of the 96 patients diagnosed with bacterial infection, seven had two simultaneous infections (six with urinary tract infections, three with bacteremia, three with rickettsiosis, one with brucellosis and one with acute gastroenteritis). Overall, 110 diagnoses of infectious diseases were made.

\section{Bacterial infections: comparison between patients with low fever $\left(38.0-39.0^{\circ} \mathrm{C}\right)$ and patients with high fever $\left(>39.0^{\circ} \mathrm{C}\right)$}

Among the 411 febrile neutropenic patients, 260 (63.3\%) and 151 (36.7\%) had fever between $38.0-39.0^{\circ} \mathrm{C}$ and fever $>39.0$ ${ }^{\circ} \mathrm{C}$, respectively. No differences were recorded between the two febrile patient groups in respect to the distribution of positive blood cultures and of specific bacterial pathogens isolated in each group, as well as the distribution of alveolar pneumonia and culture-positive urinary tract infections, gastroenteritis, septic arthritis, acute otitis media, and pharyngitis cases. No differences were found between these two groups of febrile patients in respect to the total number of patients with bacterial infections $(45 / 260,17.3 \%$ vs. $22 / 151,14.6 \%, P=$ 0.469 ), the total number of diagnoses of bacterial infections $(45 / 260,17.3 \%$ vs. $32 / 151,21.2 \%, P=0.331)$, and the total number of diagnoses of severe infectious diseases $(38 / 260$, $14.6 \%$ vs. $31 / 151,20.5 \%, P=0.122$ ).

\section{Viral infections: comparison between febrile and afebrile patients (Table 2)}

Overall, 499 nasal washings were performed and investigated by PCR for eight respiratory viruses. In addition, 82 and 83 serological tests were performed for the diagnosis of EBV and CMV, respectively; 12 PCR examinations each were performed for herpes simplex virus 1 and herpes simplex virus 2 . Two hundred and fifty-nine (51.9\%) nasal washings returned positive for respiratory viruses, with adenovirus, parainfluenza 3 , RSV, and influenza A the most common $(15.2 \%, 13.8 \%$, $8.8 \%$, and $8.8 \%$, respectively). The percentages of patients with adenovirus detection were higher in febrile patients compared with non-febrile patients $(P=0.05)$. No differences were found in the distribution of the other viral pathogens between the febrile and non-febrile neutropenic patients. A total of 688 virologic examinations were performed; of them, 295 (42.9\%) returned positive. Twenty-two patients were diagnosed with a mixed bacterial and viral infection.

When comparing patients $<2$ years of age with older patients, more nasal washings were tested in younger patients $(P$ $=0.01)$. RSV was identified in higher percentages in the group of patients $<2$ years of age ( $12.3 \%$ of all patients examined in this age group compared with $3.6 \%$ in patients $>2$ years of age, $P=0.001$ ). No differences were recorded in the percentages of other viral pathogens between patients $<2$ years of age compared with older patients.

\section{Distribution of infectious etiologies in relation to age sub-groups (Table 3)}

In the group of patients aged 61 months- 12 years, more nonfebrile patients were diagnosed with bacterial infections compared with febrile patients $(P=0.049)$. Among the patients aged 0-24 months, more febrile patients were diagnosed with viral infections compared with afebrile patients $(P=0.025)$.

\section{Relationship between temperature and severity of neutropenia in various etiologic groups (Table 4)}

No differences were recorded in the total number of patients diagnosed with infectious conditions between severely 
Table 1 Bacterial etiologies: 664 patients* (febrile vs. non-febrile) with newly diagnosed neutropenia

\begin{tabular}{|c|c|c|c|c|}
\hline & Total $n=664$ & Febrile (total) $n=411$ & Not febrile $n=253$ & $P$ value febrile vs. not febrile \\
\hline Blood cultures (bacterial) & $633(95.3)$ & $390(94.9)$ & $243(96.0)$ & 0.342 \\
\hline Positive & $12(1.9)$ & $8(2.1)$ & $4(1.6)$ & 1.000 \\
\hline Staphylococcus aureus & $4(0.6)$ & $3 / 390(0.8)$ & $1 / 243(0.4)$ & 1.000 \\
\hline Enterobacter & $2(0.3)$ & $1 / 390(0.3)$ & $1 / 243(0.4)$ & 1.000 \\
\hline Brucella & $2(0.3)$ & $2 / 390(0.5)$ & 0 & 0.526 \\
\hline Salmonella spp. & $1(0.2)$ & $1 / 390(0.3)$ & 0 & 1.000 \\
\hline Escherichia coli & $1(0.2)$ & 0 & $1 / 243(0.4)$ & 0.384 \\
\hline Acinetobacter spp. & $1(0.2)$ & 0 & $1 / 243(0.4)$ & 0.384 \\
\hline \multicolumn{5}{|l|}{ Blood cultures (fungal) } \\
\hline Candida spp. & $1(0.2)$ & $1 / 390(0.3)$ & 0 & 1.000 \\
\hline Brucellosis positive serology only (IgM/IgG)-40 tests & $19 * * / 40(47.5)$ & $\begin{array}{l}15 / 40(37.5) \\
15 / 411(3.6)\end{array}$ & $\begin{array}{l}4 / 40(10.0) \\
4 / 253(1.6)\end{array}$ & 1.000 \\
\hline Total brucellosis & 20 & $16 / 411(3.9)$ & $4 / 253(1.6)$ & 0.121 \\
\hline Rickettsia (IgM)-68 tests & $14 / 68(20.6)$ & $11 / 51(21.6)$ & $3 / 17(17.6)$ & 1.000 \\
\hline Urine cultures & $205(30.9)$ & $135 / 411(32.8)$ & $70 / 253(27.7)$ & 0.161 \\
\hline Positive & $34 / 205(16.6)$ & 20/135 (14.8) & $14 / 70(20.0)$ & 0.454 \\
\hline Escherichia coli & $22 / 205(10.7)$ & $13 / 135(9.6)$ & $9 / 70(13.0)$ & 0.613 \\
\hline Klebsiella spp. & $5 / 205(2.4)$ & $3 / 135(2.2)$ & $2 / 70(2.9)$ & 0.780 \\
\hline Other & $7 / 205(3.4)$ & $4 / 135(3.0)$ & $3 / 70(4.3)$ & 0.621 \\
\hline Positive CSF cultures (58 lumbar punctures) & 0 & 0 & 0 & - \\
\hline Stool cultures & $29(4.4)$ & 20 & 9 & \\
\hline Positive & $3 / 29(10.3)$ & $3 / 20(15.0)$ & 0 & 0.532 \\
\hline Campylobacter spp. & $2 / 29(6.9)$ & $2 / 20(10.0)$ & 0 & 1.000 \\
\hline Shigella sonnei & $1 / 29(3.4)$ & $1 / 20(5.0)$ & 0 & 1.000 \\
\hline Pneumonia (alveolar) & $16(2.4)$ & $12 / 411(2.9)$ & $4 / 253(1.6)$ & 0.405 \\
\hline Septic arthritis due to Staphylococcus aureus & 1 & $1 / 411(0.2)$ & 0 & 0.448 \\
\hline Ear cultures & 10 & $6 / 411(1.5)$ & $4 / 253(1.6)$ & 0.901 \\
\hline Positive & $2 / 10(20)$ & $2 / 6(33.3)$ & $0 / 4$ & 0.467 \\
\hline Haemophilus influenzae nontypeable & $2 / 10(20)$ & $2 / 6(33.3)$ & $0 / 4$ & 0.467 \\
\hline Pharyngeal cultures & $36(5.4)$ & 23/411 (5.6) & $13 / 253(5.1)$ & 0.800 \\
\hline Positive & $8 / 36(22.2)$ & $6 / 411(1.5)$ & $2 / 253(0.8)$ & 0.443 \\
\hline Group A Streptococcus & $6 / 36(16.7)$ & $4 / 411(1.0)$ & $2 / 253(0.8)$ & 0.809 \\
\hline Kingella kingae & $2 / 36(5.6)$ & $2 / 411(0.5)$ & 0 & 0.266 \\
\hline Impetigo & $2(0.3)$ & 0 & $2 / 253(0.8)$ & 0.07 \\
\hline Total patients with bacterial infections & $96 / 664(14.5)$ & $67 / 411(16.3)$ & $29 / 253(11.5)$ & 0.085 \\
\hline Total bacterial infections diagnoses & $110 / 664(16.6)$ & $77 / 411(18.7)$ & $33 / 253(13.0)$ & 0.091 \\
\hline Total serious bacterial infections diagnoses $* * *$ & 98/664 (14.8) & $69 / 411(16.8)$ & $29 / 253(11.5)$ & 0.060 \\
\hline
\end{tabular}

*Data missing in some patients

**1 patient had both blood culture and serology positive, 1 had only positive blood culture, 1 had only positive serology for Brucella spp.

***7 patients had 2 diagnoses of infectious disease

$\$$ Including blood, CSF, urine, and stool cultures + positive Brucella serology + positive Rickettsia serology + alveolar pneumonia

neutropenic patients and patients with mild and moderate neutropenia $\left(>500 \times 10^{9} / \mathrm{L}\right)-(P=0.557)$. In patients with an infectious etiology, no differences were found between severely neutropenic patients and patients with mild and moderate neutropenia in the percentages of febrile and non-febrile patients $(P=0.488)$. No differences were also found when comparing the distribution of the various infectious etiologies (bacterial, viral, and mixed) between severely neutropenic patients and patients with mild and moderate neutropenia and also between febrile and non-febrile patients. 
Table 2 Viral etiologies: comparison between febrile and non-febrile patients

\begin{tabular}{|c|c|c|c|c|c|}
\hline Etiology & $\begin{array}{l}\text { Total examinations } \\
\text { performed }\end{array}$ & $\begin{array}{l}\text { Positive (total) } \\
n(\%)\end{array}$ & $\begin{array}{l}\text { Positive febrile } \\
n(\%)\end{array}$ & $\begin{array}{l}\text { Positive non- } \\
\text { febrile } n(\%)\end{array}$ & $\begin{array}{l}P \\
\text { value }\end{array}$ \\
\hline Nasal washes & 499 & 259 (51.9) & $\begin{array}{c}173 / 322 * \\
(53.7)\end{array}$ & $86 / 177 * *(48.6)$ & 0.246 \\
\hline RSV & 499 & $44(8.8)$ & $23 / 322(7.1)$ & 21/177 (11.9) & 0.106 \\
\hline Adenovirus & 499 & $76(15.2)$ & $57 / 322(17.7)$ & $19 / 177$ ( 10.7) & 0.05 \\
\hline Influenza A & 499 & $44(8.8)$ & $26 / 322(8.1)$ & $18 / 177(10.2)$ & 0.532 \\
\hline Influenza B & 499 & $19(3.8)$ & $15 / 322(4.7)$ & 4/177 (2.3) & 0.274 \\
\hline Parainfluenza 1 & 499 & $25(5.0)$ & $16 / 322(5.0)$ & $9 / 177(5.1)$ & 1.000 \\
\hline Parainfluenza 2 & 499 & $14(2.8)$ & $11 / 322(3.4)$ & 3/177 (1.7) & 0.397 \\
\hline Parainfluenza 3 & 499 & $19(13.8)$ & $13 / 322(4.0)$ & 6/177 (3.4) & 0.907 \\
\hline Metapneumovirus & 499 & $18(3.6)$ & $12 / 322(3.7)$ & $6 / 177$ ( 3.4$)$ & 1.000 \\
\hline EBV & 82 & $17(20.7)$ & $13 / 57(22.8)$ & $4 / 25(16.0)$ & 0.685 \\
\hline CMV & 83 & $18(21.7)$ & $12 / 56(21.4)$ & $6 / 27(22.2)$ & 1.000 \\
\hline Herpes simplex 1 & 12 & $1(8.3)$ & $1 / 7(14.3)$ & $0 / 5$ & 1.000 \\
\hline Herpes simplex 2 & 12 & 0 & 0 & 0 & \\
\hline
\end{tabular}

*Total nasal washings in febrile patients

**Total nasal washings in afebrile patients

\section{Malignancies}

Six $(0.9 \%)$ of the 664 enrolled patients were diagnosed during hospitalization with malignancy (acute leukemia in all six). Of them, three were $<15$ months of age, three were of Jewish ethnicity/three were of Bedouin ethnicity and three had a fever $>38.0^{\circ} \mathrm{C}$ at admission. The ANC in five of them was between 1.06 and $1.34 \times 10^{9} / \mathrm{L}$ and was $0.56 \times 10^{9} / \mathrm{L}$ in the sixth patient. Anemia was recorded in one patient and thrombocytopenia in one additional patient. An infectious etiology was
Table 3 Infectious etiology according to age groups*

\begin{tabular}{lllll}
\hline Etiology & Total positive $n(\%)$ & Febrile $^{\#} n(\%)$ & Non febrile $n(\%)$ & $P$ value \\
\hline Bacterial only** & & & & \\
$0-24 \mathrm{~m}(n=425)$ & $38 / 413(9.2)$ & $26 / 264(9.8)$ & $12 / 161(7.5)$ & 0.401 \\
$25-60 \mathrm{~m}(n=125)$ & $8 / 119(6.7)$ & $7 / 80(8.8)$ & $1 / 45(2.2)$ & 0.152 \\
$61 \mathrm{~m}-12$ years $(n=48)$ & $6 / 46(13.0)$ & $1 / 26(3.8)$ & $5 / 22(22.7)$ & 0.049 \\
$>12$ years $(n=66)$ & $3 / 61(4.9)$ & $2 / 41(4.9)$ & $1 / 25(4.0)$ & 0.868 \\
Viral only*** & & & \\
$0-24 \mathrm{~m}(n=425)$ & $133 / 296(44.9)$ & $93 / 264(35.2)$ & $40 / 161(24.8)$ & 0.025 \\
$25-60 \mathrm{~m}(n=125)$ & $66 / 98(67.3)$ & $42 / 80(52.5)$ & $24 / 45(53.3)$ & 0.929 \\
$61 \mathrm{~m}-12$ years $(n=48)$ & $17 / 34(50)$ & $8 / 34(23.5)$ & $9 / 22(40.9)$ & 0.167 \\
$>12$ years $(n=66)$ & $11 / 46(23.9)$ & $8 / 46(17.4)$ & $3 / 25(12.0)$ & 0.549 \\
Mixed infection (bacterial and viral pathogen together) & & & \\
$0-24 \mathrm{~m}(n=425)$ & $18 / 286(6.3)$ & $13 / 264(4.9)$ & $5 / 161(3.1)$ & 0.366 \\
$25-60 \mathrm{~m}(n=125)$ & $3 / 92(3.3)$ & $3 / 80(3.8)$ & $0 / 45(0)$ & 0.189 \\
$61 \mathrm{~m}-12$ years $(n=48)$ & $1 / 32(3.1)$ & $1 / 34(2.9)$ & $0 / 22(0)$ & 0.417 \\
$>12$ years $(n=66)$ & $0 / 42(0)$ & $0 / 46(0)$ & $0 / 25(0)$ & - \\
\hline
\end{tabular}

* Data missing for some patients (blood cultures and viral testing not performed in all patients); serology performed in accordance with clinical indications

**Bacterial only group include: positive blood, urine, CSF, joint, stool, pharyngeal, and/or ear culture + diagnosis of pneumonia (alveolar) + positive Brucella serology + positive Rickettsia serology

***Viral only: positive nasal wash, positive EBV and CMV serology, and/or PCR and positive HSV-PCR***

${ }^{\$}$ The denominator represents the number of patients tested for the respective etiology among the respective age group

\#The denominator represents the number of febrile or non-febrile patients in each age group 
Table 4 Relationship between temperature and severity of neutropenia in various etiologic groups (data not available for all patients)

\begin{tabular}{|c|c|c|c|}
\hline Etiology & $\begin{array}{l}\mathrm{ANC}^{*}<500 \\
\left(\times 10^{9} / \mathrm{L}\right) N=\end{array}$ & $\begin{array}{l}\mathrm{ANC}>500 \\
\left(\times 10^{9} / \mathrm{L}\right) N=\end{array}$ & $P$ value \\
\hline Bacterial only** & $8 / 92(8.7)$ & $69 / 551(12.5)$ & 0.383 \\
\hline Febrile & $7 / 8(87.5)$ & $47 / 69(68.1)$ & \\
\hline Non-febrile & $1 / 8(12.5)$ & $22 / 47(31.9)$ & 0.423 \\
\hline Viral only*** & $37 / 68(54.4)$ & $189 / 406(46.6)$ & 0.285 \\
\hline Febrile & $26 / 37(70.3)$ & $125 / 189(66.1)$ & \\
\hline Non-febrile & $11 / 37(29.7)$ & $64 / 189(33.9)$ & 0.766 \\
\hline Mixed infection (bacterial and viral agent together) & $3 / 67(4.5)$ & $20 / 389(5.1)$ & 1.000 \\
\hline Febrile & $2 / 3(66.70$ & $15 / 20(75.0)$ & \\
\hline Non-febrile & $1 / 3(33.3)$ & $5 / 20(25)$ & 1.000 \\
\hline Infectious etiology & $49 / 93(52.7)$ & $278 / 568(48.9)$ & 0.557 \\
\hline Febrile & $36 / 49(73.5)$ & $187 / 278(67.3)$ & \\
\hline Non-febrile & $13 / 49(26.5)$ & $91 / 278(32.7)$ & 0.488 \\
\hline \multicolumn{4}{|l|}{$A N C$, absolute neutrophil count } \\
\hline
\end{tabular}

determined in four patients (one with RSV bronchiolitis, one with acute otitis media caused by $H$. influenzae non-typeable, one with mixed adenovirus and CMV infection and one with brucellosis and influenza $\mathrm{A}+\mathrm{B}$ infection).

\section{Follow-up (Table 5)}

A follow-up WBC count was retrieved in 323 (48.6\%) patients during the time period of 1 month after the initial WBC count. Neutropenia resolved in 163/323 (50.5\%). In patients with viral etiology, the number of patients with resolution of neutropenia was lower than the number of patients without resolution of neutropenia (42.5\% vs. $72.1 \%, P<0.001$ ). No differences were recorded between patients with resolution of neutropenia compared with patients without resolution of neutropenia among children with bacterial and mixed etiologies. No differences were recorded in the percentages of patients with resolution of neutropenia compared with patients without resolution of neutropenia among all four severity groups. No differences were recorded in the rates of neutropenia resolution between febrile and non-febrile children among all four severity groups.

Table 6 presents a multi-variate analysis by Cox regression predicting the resolution of neutropenia as a function of fever at the time of diagnosis, patient age $(0-2$ years and $>2$ years of age), and severity of neutropenia. No significant differences were recorded in the rates of resolution of neutropenia as a function of these three parameters.

Figure 1 compares the resolution of neutropenia between febrile and non-febrile patients; no differences were found in the resolution of neutropenia between the two groups $(P=0.166)$.
Figure 2 compares the resolution of neutropenia between patients with fever of $38.0-39.0{ }^{\circ} \mathrm{C}$ and those with fever $>$ $39.0{ }^{\circ} \mathrm{C}$; no differences were found in the resolution of neutropenia between the two groups $(P=0.244)$.

Figure 3 compares the resolution of neutropenia between the 3 different severity degree groups $(<500,500-1000$, and $>$ 1000 cells $\left.\times 10^{9} / \mathrm{L}\right)$; no differences were found in the resolution of neutropenia between the three groups $(P=0.509)$.

\section{Discussion}

In a recent study published by our group in 2018, David et al. [18], reported on 601 non-immunocompromised infants and children aged $<18$ years hospitalized during 2010-2012 with acute neutropenia and found that $>50 \%$ of the patients were $<$ 2 months of age and $27.6 \%$ were febrile at admission. The WBC count showed severe neutropenia in $8 \%$ of patients, moderate neutropenia in $27.5 \%$, and mild neutropenia in $64.6 \%$ of patients. SBIs were diagnosed in $17.9 \%$ of patients. Brucella and Rickettsia spp. were diagnosed in $15.4 \%$ and $23.1 \%$ of patients evaluated for these conditions. Virologic studies from nasopharyngeal washings were performed in 69 (11.4\%) patients with identification of RSV in $51.5 \%$ of all positive samples. Overall, an infectious condition (diagnosed by culture, antigen diagnosis, serology, chest x-ray, PCR, and clinical picture) was found in $30.9 \%$ patients. Six (1\%) patients were diagnosed with acute leukemia. The median length of hospitalization was 2.3 days (10.3 days in patients with neutropenia $<200 \times 10^{9} / \mathrm{L}$ ). No differences were recorded in the various infectious etiologies between patients with severe 
Table 5 A one-month follow-up on neutropenia by age, etiology and severity of neutropenia

\begin{tabular}{|c|c|c|c|c|}
\hline & Number of patients investigated (\%) & Neutropenia Resolved (\%) & Neutropenia not resolved (\%) & $P$ value \\
\hline Patients with follow-up CBC & $323 / 664$ (48.6) & $163(50.5)$ & $160(49.5)$ & \\
\hline Febrile & $207 / 323(64.5)$ & $100 / 163(61.3)$ & $107 / 160(66.9)$ & \\
\hline Non-febrile & $116 / 323(35.9)$ & $63(38.7)$ & $53(33.1)$ & 0.358 \\
\hline \multicolumn{5}{|l|}{ Etiology } \\
\hline Bacterial only* & $38 / 314(12.1)$ & $22 / 159(13.8)$ & $16 / 155(10.3)$ & 0.435 \\
\hline Febrile & $28 / 38(73.7)$ & $15 / 22(68.2)$ & $13 / 16(81.3)$ & \\
\hline Non-febrile & $10 / 38(26.3)$ & $7 / 22(31.8)$ & $3 / 16(18.8)$ & 0.469 \\
\hline Viral only** & $256 / 323(79.3)$ & $54 / 127(42.5)$ & $93 / 129(72.1)$ & $<0.001$ \\
\hline Febrile & $100 / 256(39.1)$ & $37 / 54(68.5)$ & 63/93 (67.70 & \\
\hline Non-febrile & $47 / 256(18.4)$ & $17 / 54(31.5)$ & $30 / 93(32.3)$ & 1.000 \\
\hline Mixed infection & $19 / 247(7.7)$ & $10 / 123(8.1)$ & $9 / 124(7.3)$ & 0.985 \\
\hline Febrile & $14 / 19(73.7)$ & $7 / 10(70)$ & 7/9 (77.8) & \\
\hline Non-febrile & $5 / 19(26.3)$ & $3 / 10(30)$ & $2 / 9(22.2)$ & 1.000 \\
\hline \multicolumn{5}{|l|}{ Severity of neutropenia } \\
\hline $\mathrm{ANC}^{* * *} \leq 200$ cells $\times 10^{9} / \mathrm{L}$ & $15 / 323(4.7)$ & $7 / 163(4.3)$ & $8 / 160(5.0)$ & 0.763 \\
\hline Febrile & $13 / 15(86.7)$ & $6 / 7(85.7)$ & $7 / 8(87.5)$ & \\
\hline Non-febrile & 2/15 (13.3) & $1 / 7(14.3)$ & $1 / 8(12.5)$ & 1.000 \\
\hline $\mathrm{ANC}=201-500$ cells $\times 10^{9} / \mathrm{L}$ & 36/323 (11.1) & $17 / 163(10.4)$ & 19/160 (11.9) & 0.680 \\
\hline Febrile & $24 / 36(66.7)$ & $14 / 17(82.4)$ & $10 / 19(52.6)$ & \\
\hline Non-febrile & $12 / 36(33.3)$ & 3/17 (17.6) & 9/19 (47.4) & 0.125 \\
\hline $\mathrm{ANC}=501-1000$ cells $\times 10^{9} / \mathrm{L}$ & $107 / 323(33.1)$ & $55 / 163(33.7)$ & $52 / 160(32.5)$ & 0.813 \\
\hline Febrile & $66 / 107(61.7)$ & $31 / 55(56.4)$ & $35 / 52(67.3)$ & \\
\hline Non-febrile & 41/107 (38.3) & $24 / 55(43.6)$ & $17 / 52(32.7)$ & 0.335 \\
\hline ANC $>1000$ cells $\times 10^{9} / \mathrm{L}$ & $165 / 323(51.1)$ & $84 / 163(51.5)$ & $81 / 160(50.6)$ & 0.870 \\
\hline Febrile & $104 / 165(63.0)$ & 49/84 (58.3) & $55 / 81(67.9)$ & \\
\hline Non-febrile & $61 / 165(37.0)$ & $35 / 84(41.7)$ & 26//81 (32.1) & 0.266 \\
\hline
\end{tabular}

*Bacterial only group include: positive blood culture (not including brucellosis), urine culture, CSF culture, joint culture, stool culture, pharyngeal culture, and ear culture + diagnosis of pneumonia

**Viral only: positive nasal wash, positive EBV and CMV serology, and positive HSV PCR

$* * *$ ANC $=$ absolute neutrophil count

neutropenia compared with those with mild or moderate neutropenia. A direct association was found between length of neutropenia, infectious etiology, and severity of neutropenia.

The purpose of the present study was to describe the epidemiological, etiological, clinical, laboratory, and outcome characteristics in a large number of non-immunocompromised patients hospitalized with acute neutropenia. In this study, we paid special emphasis to a comparison between patients with non-febrile versus those with febrile neutropenia, an important topic not analyzed previously in the pediatric medical literature.

Specifically, we looked after the infectious and noninfectious etiology of acute neutropenia diagnosed in the

Table 6 Correction of neutropenia during a 1-month follow-up period, as function of maximum temperature at admission, degrees of temperature (fever between $38-39^{\circ} \mathrm{C}$ and $>39^{\circ} \mathrm{C}$ ) and severity of neutropenia: multivariate analysis by Cox regression

Variables in the equation

\begin{tabular}{|c|c|c|c|c|c|c|c|c|}
\hline & \multirow[t]{2}{*}{$\mathrm{B}$} & \multirow[t]{2}{*}{ SE } & \multirow[t]{2}{*}{ Wald } & \multirow[t]{2}{*}{ df } & \multirow[t]{2}{*}{ Sig. } & \multirow[t]{2}{*}{$\operatorname{Exp}(B)$} & \multicolumn{2}{|c|}{$95.0 \%$ CI for $\operatorname{Exp}(B)$} \\
\hline & & & & & & & Lower & Upper \\
\hline Maximum temperature (at home and at admission) (2 Sub-Groups) & -0.223 & 0.161 & 1.916 & 1 & 0.166 & 0.800 & 0.583 & 1.097 \\
\hline Neut_ABS $\leq 500$ cells $\backslash \mathrm{mm} 3$ & 0.118 & 0.221 & 0.285 & 1 & 0.593 & 1.126 & 0.729 & 1.737 \\
\hline Age Group 2 subgroups (at hospitalization) & -0.254 & 0.167 & 2.295 & 1 & 0.130 & 0.776 & 0.559 & 1.077 \\
\hline
\end{tabular}


Fig. 1 Comparison between the resolution of neutropenia in febrile $v s$. non-febrile patients

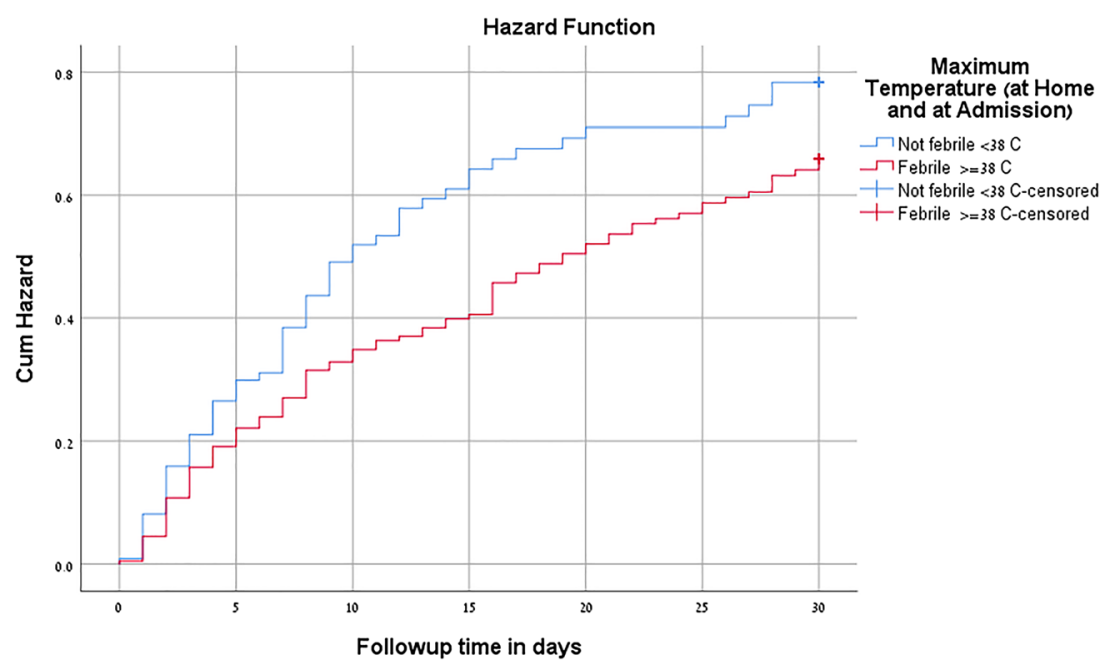

pediatric emergency room, patient distribution according to age, severity of neutropenia and its resolution, and analyzed these parameters as a function of presence or absence of fever at admission. While in the previous study [18] the number of patients investigated for a viral etiology of the condition was small, we performed in the present study extensive investigations for the detection of various viral infections, leading to more definitive viral diagnoses associated with acute neutropenia. Furthermore, we followed the study patients for a onemonth period after their discharge and analyzed the resolution of neutropenia as a function to its severity and association/lack of association with fever at admission.

We found that the number of patients with acute neutropenia and $<2$ years of age was high $(64 \%)$ and the number of cases with severe neutropenia was low (14.3\%). Infectious diseases in general and also bacterial infectious disease (14.5\%) and SBIs (14.8\%) were recorded in a considerable number of patients, with a trend for higher percentages of the last two conditions in febrile patients compared with nonfebrile patients. In addition, a considerable number of cases of acute neutropenia in this study were associated with brucellosis and rickettsiosis. A definitive viral diagnosis was made in a considerable number $(42.9 \%)$ of the study patients, with higher rates of adenovirus isolations in febrile compared with non-febrile patients and higher rates of RSV isolations in children $<2$ years of age compared with older ages. When comparing patients with severe, moderate, or mild neutropenia; no differences were recorded in the distribution of various infectious etiologies and the number of febrile or non-febrile patients. Malignancies (acute leukemia in all cases) were diagnosed in $0.9 \%$ patients with acute neutropenia. Resolution of neutropenia during the one-month follow-up period after hospitalization was achieved in $50.5 \%$ of patients, with no differences in the resolution rates as a function of the severity of neutropenia and presence or lack of fever at admission. In patients with viral etiology, the number of patients with resolution of neutropenia was lower than the number of patients without resolution of neutropenia during the follow-up period.

Information on the viral etiology associated with acute neutropenia episodes (febrile or non-febrile at diagnosis) in
Fig. 2 Comparison between resolution of neutropenia in patients with fever of 38.0 $39.0^{\circ} \mathrm{C}$ and those with fever $>$ $39.0^{\circ} \mathrm{C}$

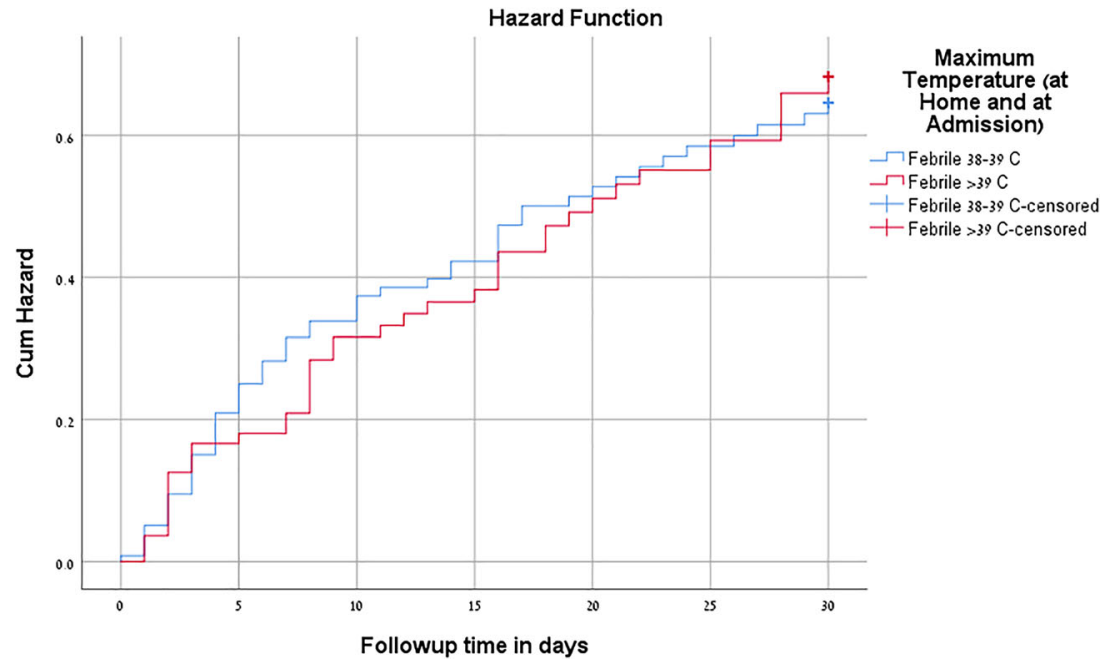


Fig. 3 Comparison between resolution of neutropenia among the 3 different severity groups $(<500,500-1000$ and $>1000$ cells $\left.\times 10^{9} / \mathrm{L}\right)$

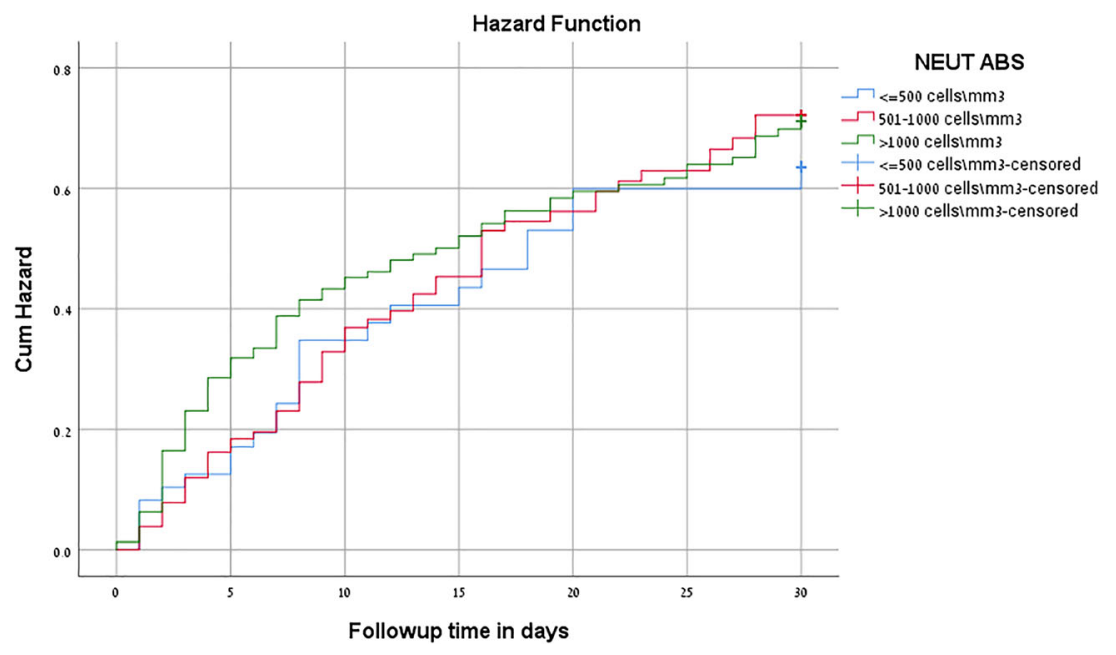

immunocompetent children is limited. The relevant information about the association between viral etiologies and acute neutropenia derives mainly from the analysis of cases of fever and neutropenia in immunocompromised patients with malignancies. In a study from 2016 [26] which examined the results of nasal washings in 87 febrile neutropenia episodes in oncological children, real-time PCR for identification of 16 respiratory viruses detected such viruses in 39 (45\%) episodes and rhinoviruses were the most frequently isolated ones. A repeated PCR examination established that the viral infection disappeared in $78 \%$ of episodes after a mean of 28 days. In another study from 2016 [27], 1044 febrile episodes were recorded in 525 children suffering from malignancies during a five-year period in three hospitals in Chile. Seventeen respiratory viruses were looked after by PCR performed in nasal washings and at least one respiratory virus was identified in $46 \%$ of the neutropenic episodes. The most commonly identified viruses (in decreasing order) were rhinovirus, RSV, parainfluenza, influenza, adenovirus, and human metapneumovirus. The authors reported on a benign course of all episodes of neutropenia where a respiratory virus was identified, as a single pathogen or in the combination of two or more viruses [27].

We performed a considerable number of viral examinations among the study patients, including PCR for respiratory viruses in nasal washings, serological testing for EBV and $\mathrm{CMV}$, and PCR from skin lesions and blood samples for herpes viruses. More than $50 \%$ nasal washings returned positive for respiratory viruses, with adenovirus, parainfluenza 3, $\mathrm{RSV}$, and influenza A, reported as the most common $(15.2 \%, 13.8 \%, 8.8 \%$, and $8.8 \%$, respectively). The percentages of patients with adenovirus detection were higher in febrile patients compared with non-febrile patients and no differences were found in the distribution of the other viral pathogens between febrile and non-febrile neutropenic patients. Our results suggest that viruses play a major role in the etiology of acute neutropenia not only in immunocompromised, but also in immunocompetent children, and their early detection may be crucial in the management of these cases by withholding empiric antibiotic administration, even in not toxic-looking patients with severe neutropenia.

We found in our study that the rates of bacterial infections (including SBIs) were higher in febrile patients compared with non-febrile ones. These rates are higher than the rates previously reported in the literature and raised the possibility of a more severe disease in neutropenic febrile patients compared with those without fever. These findings require further confirmation in additional studies and add also additional questions with respect to the need for empiric antibiotic treatment in febrile patients. On the other hand, we report in the present study that the severity of neutropenia and also its resolution (during a short one-month follow-up) are not associated with the presence or absence of fever at diagnosis of neutropenia. However, a viral etiology was associated with lower rates of resolution of neutropenia during the follow-up period and we consider that further studies with a longer follow-up of the WBC counts are necessary in order to clarify this issue.

In addition, the higher rates of bacterial infections and SBIs reported in our study may be also related to the high rates of brucellosis and rickettsiosis diagnoses among the study population (representing together $34.7 \%$ of the patients with a diagnosis of SBI). These findings confirm previous data that brucellosis is a common disease in southern Israel and additional efforts are needed for its prevention [23, 24]. In Israel, two types of Rickettsia species are described as endemic (R. typhi and R. conorii) $[28,29]$. The clinical picture of rickettsiosis is not specific, with fever, weakness, muscular pain, and a specific rash in most cases. However, among the Bedouin population living in southern Israel, the disease caused by $R$. typhi does not present with a rash in most cases and is more difficult to diagnose [25]. Among the patients enrolled in our series of acute neutropenia, we found 14 cases diagnosed with rickettsiosis by serologic examination without any skin manifestations. The hematologic findings in rickettsiosis are not rare; Shalev et al. [25] described in 2006 
rates of $68.4 \%, 18.4 \%$, and $6.6 \%$ of anemia, leukopenia, and thrombocytopenia, respectively, among 76 children diagnosed with this disease. According to our findings and similar to the cases of brucellosis previously described, the diagnosis of rickettsiosis should be looked after in children presenting with acute neutropenia, at least in specific geographic areas where these two conditions are common.

The limitations of our study are mainly related to its retrospective nature, which may have contributed to some lacking or missing information on the enrolled patients. In addition, we cannot rule out that some of the patients enrolled in our study might have suffered from ethnical neutropenia (as described in some populations) and not diagnosed previously [30-32]. Regarding the categorization of the enrolled patients as previously immunocompetent, this categorization was of course challenging and it could be argued that in some cases, like in those with neutropenia associated with bacteremia, a previously temporary immunodeficiency status might have occurred in the body innate defenses, permitting, therefore, the access of the pathogens to the bloodstream. Another limitation is related to lack of follow-up data for a considerable number of patients enrolled in the study and, as mentioned, the lack of a longer follow-up period with repeated WBC counts after discharge from hospital.

In conclusion, we found in this study that severe neutropenia was rare and most of the cases occurred in very young patients. SBIs were found in higher percentages among febrile patients compared with non-febrile patients, but we did not find an association between the severity of neutropenia and its resolution during the follow-up period with the presence or absence of fever at the time of diagnosis. Brucellosis and rickettsiosis were frequent SBIs associated with neutropenia in southern Israel.

\section{Compliance with ethical standards}

Conflict of interest The authors declare that they have no conflict of interest.

Ethical approval The research protocol was approved by the Ethics Committee of the Soroka University Medical Center.

Informed consent Retrospective research, informed consent not needed

\section{References}

1. Dallman PR (1977) Neutropenia. In Pediatrics Rudolph AM (Ed), Appleton-Century-Crofts, New York. p. 1178.

2. Bodey GP, Buckley M, Sathe YS et al (1966) Quantitative relationships between circulating leukocytes and infection in patients with acute leukemia. Ann Intern Med 64:328-340

3. Petrilli AS, Melaragno R, Barros KV et al (1993) Fever and neutropenia in children with cancer: a therapeutic approach related to the underlying disease. Pediatr Infect Dis J 12:916-921
4. Meckler G, Lindemulder S (2009) Fever and neutropenia in pediatric patients with cancer. Emerg Med Clin North Am 27:525-544

5. Vlacha V, Feketea G (2007) The clinical significance of nonmalignant neutropenia in hospitalized children. Ann Hematol 86: 865-870

6. Sung L, Johnston DL (2007) Approach to febrile neutropenia in the general paediatric setting. Paediatr Child Health 12(1):19-21

7. Lindqvist H, Carlsson G, Moell J, Winiarski J, Sundin M (2015) Neutropenia in childhood: 5-year experience at a tertiary center. Eur J Pediatr 174:801-807

8. Alario AJ, O'Shea JS (1989) Risk of infectious complications in well-appearing children with transient neutropenia. Am J Dis Child 143:973-976

9. Bonadio WA, Smith DS, Mathews S, Rock AL (1991) Clinical significance of newly documented neutropenia in febrile young infants evaluated for sepsis. Pediatr Infect Dis J 10(5):407-411

10. Perez-Mendes C, Molinis-Norniella C, Moran-Poladura M, Fernandez-Rodriguez E, Suarez-Castanon C, Solis-Sanchez G (2010) Low risk of bacteremia in otherwise healthy children presenting with fever and severe neutropenia. Pediatr Infect Dis J 29: 671-672

11. Melendez E, Harper MB (2010) Risk of serious bacterial infection in isolated and unsuspected neutropenia. Acad Emerg Med 17(2): 163-167

12. Husain EH, Mullah-Ali A, Al-Sharidah S, Azab AF, Adekile A (2012) Infectious etiologies of transient neutropenia in previously healthy children. Pediatr Infect Dis J 31:575-577

13. Alexandropoulou O, Kossiva L, Haliotis F, Giannaki M, Tsolia M, Panagiotou IP et al (2013) Transient neutropenia in children with febrile illness and associated infectious agents: 2 years follow-up. Eur J Pediatr 172:811-819

14. Alexandropoulou O, Kossiva L, Giannaki M, Panagiotou JP, Tsolia M (2014) Karavanaki K.14. The epidemiology, clinical course and outcome of febrile cytopenia in children. Acta Paediatr 104:e112 e118

15. Barg AA, Kozer E, Mordish Y, Lazarovitch T, Kventsel I, Goldman M (2015) The risk of serious bacterial infection in neutropenic immunocompetent febrile children. J Pediatr Hematol Oncol 37:e347-e351

16. Pascual C, Trenchs V, Hernandes-Bou S, Catala A, Valls AF, Luaces C (2016) Outcome and infectious etiologies of febrile neutropenia in non-immunocompromized children who present in an emergency department. Eur J Clin Microbiol Infect Dis. https://doi. org/10.1007/s10096-016-2708-7

17. Wittmann O, Rimon A, Scolnik D, Glatstein M (2017) Outcomes of immunocompetent children presenting with fever and neutropenia. J Emerg Med 54:315-319

18. David O, Fruchtman Y, Sergienko R, Kapelushnik J, Leibovitz E (2018) The infectious and noninfectious etiology, clinical picture and outcome of neutropenia in immunocompetent hospitalized children. Pediatr Infect Dis J 37(6):570-575. https://doi.org/10.1097/ INF.0000000000001893

19. Segel GB, Halkterman S (2008) Neutropenia in pediatric practice. Pediatr Rev 29:12-23

20. Dagan R, Powell KR, Hall CB et al (1985) Identification of infants unlikely to have serious bacterial infection although hospitalized for suspected sepsis. J Pediatr 107:855-860

21. Baraff LJ, Bass JW, Fleisher GR et al (1993) Practice guideline for the management21. of infants and children 0 to 36 months of age with fever without source. Agency for Health Care Policy and Research. Ann Emerg Med 22:1198-1210

22. Lieberman D, Lieberman D, Shimoni A, Keren-Naus A, Steinberg $\mathrm{R}$, Shemer-Avni V (2009) Identification of respiratory viruses in adults: nasopharyngeal versus oropharyngeal sampling. J Clin Microbiol 47:3439-3443 
23. Shemesh AA, Yagupsky P (2012) Isolation rates of Brucella melitensis in an endemic area and implications for laboratory safety. Eur J Clin Microbiol Infect Dis 31:441-443.23

24. Fruchtman Y, Wilkof-Segev R, Asher-Golan A, Dalem Y, Tailakh MA, Novak V et al (2015) Epidemiological, diagnostic, clinical and therapeutic aspects of Brucella bacteremia in children in Southern Israel: a 7-year retrospective study (2005-2011). Vector Borne Zoonotic Dis 15:195-201

25. Shalev H, Rotkane R, Zislin E, Yagupsky P (2006) Murine typhus is a common cause of febrile illness in Bedouin children in Israel. Scand J Infect Dis 38:451-455

26. Söderman M, Rhedin S, Tolfvenstam T, Rotzén-Östlund M, Albert J, Broliden K, Lindblom A (2016) Frequent respiratory viral infections in children with febrile neutropenia - a prospective follow-up study. PLoS One 11(6):e0157398. https://doi.org/10.1371/journal. pone.0157398.eCollection2016

27. Torres JP, De la Maza V, Kors L, Villarroel M, Piemonte P, Izquierdo $G$ et al (2016) Respiratory viral infections and coinfections in children with cancer, fever and neutropenia: clinical outcome of infections caused by different respiratory viruses. Pediatr Infect Dis J 35:949-954. https://doi.org/10.1097/INF. 0000000000001209
28. Rovery C, Raoult D (2008) Mediterranean spotted fever. Infect Dis Clin N Am 22:515-530 ix

29. Rogozin E, Lazarovitch T, Weinberger M (2019) High morbidity due to murine typhus upsurge in urban neighborhoods in Central Israel. Am J Trop Med Hyg 100(4):952-956. https://doi.org/10. 4269/ajtmh.18-0076

30. Caramihai E, Karayalcin G, Aballi AJ, Lanzkowsky P (1975) Leukocyte count differences in healthy white and black children 1 to 5 years of age. J Pediatr 86:252-254

31. Shoenfeld Y, Alkan ML, Asaly A, Carmeli Y, Katz M (1988) Benign familial leukopenia and neutropenia in different ethnic groups. Eur J Haematol 41:273-277

32. Rappoport N, Simon AJ, Lev A, Yacobi M, Kaplinsky C, Weingarten $\mathrm{M}$ et al (2015) Correlation between 'ACKR1/DARC null' polymorphism and benign neutropenia in Yemenite Jews. Br J Haematol 170:892-895

Publisher's note Springer Nature remains neutral with regard to jurisdictional claims in published maps and institutional affiliations. 